\title{
The Role of Politeness in the Employee-client Speech Interactions
}

\author{
Kaveh Hedayat \\ Department of Linguistics, Central Tehran Branch, Islamic Azad University, Tehran, Iran \\ Foroogh Kazemi \\ Department of Linguistics, Central Tehran Branch, Islamic Azad University, Tehran, Iran
}

\begin{abstract}
The current investigation intends to study the pragmatic role of politeness in the interactions between employers with some clients in governmental offices. In linguistic interactions, the role of metalinguistic factors like linguistic ones are so noticeable and also can be rendered. In this study, we collected data by field method and by means of a questionnaire. Also the method of research was analytical one. The statistical society was one hundred person of the governmental clients. The results suggest that meanwhile the conversation, using face to face interactions and making utterance was satisfactory, but speech interruption was seen for35 items, 12 items for keep client waiting, 21 items for ambiguous talking and paying enough attention to client's discourse was merely 38 items. Today the result of the study shows that the clients expect that their face to be preserved and the staff offices must implement the pragmatics strategies of politeness and face saving in format of positive and negative face in order to have a more effect on the clients. Maybe most of us didn't think so far to the point that we must speak due to the necessities, and these necessities should be found in every one's context of situation.
\end{abstract}

Index Terms - pragmatics, discourse, politeness, metalinguistic factors

\section{INTRODUCTION}

Language is everything; a communicative system, a thought transferor, a means to express politeness, a social quality, a basis in politics and one of the elements of forming the nations. The human beings all know at least one language. The imagination of realizing social and mental abilities without language is almost impossible. Therefore, each of us benefit from language organization and its usage (O'Grady, 1989). The study of pragmatics can be made possible in communication. There is a consensus of agreement that pragmatic knowledge is necessary in order to understand and use language (Ibid). Regarding Grice's cooperative principle, Leech (1983, p. 5) maintained that an abstract discussion of cooperative principle doesn't suffice rather it should be studied regarding politeness principle. Leech (1983) believed that the necessity of cooperative principle should be basically impinged. He continued that the cooperative principle is appropriate for the justification of the relationship between face and intended meaning, especially where semantics is difficult to comprehend. This principle, however, cannot answer the question why human beings speak indirectly. He finally concluded that Grice's cooperative principle isn't applicable alone and it should be accompanied by the principle of "polite language" or "politeness in language". By providing some examples, he asserted that the principle of politeness in language can, in most of the cases, compensate for the inefficiencies of Grice's cooperative principle.

Language has different roles, and one use it in different official or none-official styles in order to make a communication. In this regard, metalinguistic factors together with linguistic ones, like grammatical structures and lexicon and so on, have an important role in language and in make communications as a whole. The issue of the current study is that what linguistic and metalinguistic strategies (pragmatics) are used between the employers and clients within a discourse's framework that is effective in making communications? The current study searches the answer to the question that what is the role of politeness as a meta-language factor in linguistic factors between employers and clients in the governmental offices? Making communication (whether linguistic or metalinguistic) with people in office's staff, affects people's judgments about them. Various linguistic interactions can facilitate the employer-client relations, or make it difficult.

The business world is today based upon customer orientation and satisfaction to the extent that development and providing services is almost impossible without considering this. Customer-oriented organizations believe in the sentence "customer is always right". Respect for the customer has become popular in the world for many years. Indeed the difficulties in organizations are not important for the customers rather they are looking for organizations that solve their problems. Customer-oriented organization is an organization that has targeted solving these problems and they believe that customer satisfaction is both the wealth of the organization and a guarantee for the return of organization capital. With improve the discourse level in order to offer more effective services to the client and due to the importance of politeness and its effect in official discourse to have a better relationship with client, it is essential to do a more efficient research in his regard. This article tries to investigate the effects of the linguistic and meta-linguistic factors in 
the discourse and discourse analysis scope, since observing politeness may has a good effect on the offering service to the clients in organizations. In this article, data collection was done through field method and questionnaires, and the survey was an analytic one. The statistical society was of 100 persons of the clients in none-private offices in five central regions that is, of north, east, west, and south and center of Tehran. The reason for choosing this statistical society, was that the variables be chosen from different kinds of cultures, so that the results be the most reliable ones.

\section{REVIEW OF THE RELEVANT STUDIES}

Felix and Defer (2005) did a research on the area of politeness and indirectness in the west, named "indirectness and politeness in the Mexican request". In this study, they surveyed the amount of existing anathemas among people and politeness relevance and their relations with indirectness. They don't agree with Brown and Levinson theory that says indirectness indicates politeness and made into conclusion that Mexican speakers used direct sentences in their conversations, that don't indicate impoliteness in discourse, rather suggesting a kind of an intimacy relation among them. Other research is in the field of politeness and indirectness conducted by Marti (2006) as "politeness and directness in the requests of the German - Turkish bilinguals and mono and Turkish bilinguals". He wants to know why the most Turkish people consider those who have return from Germany to their home town after years such as Marti as direct and even disrespectful. The findings of this study are based on the Blum Kulka's (1987) theories and shows that there is no linear connection between politeness and indirectness. Ogiremann (2007) studied the concepts of politeness and directness in a study titled "politeness and indirectness in cultures: A comparison of English, German, Polish, and Russian requests". After investigating the similarities and differences between English, German, Polish, and Russian culture, finally he concluded that there is more requests of Polish and Russian, compared to English and German languages, and as a whole, the two concepts of politeness and indirectness are different in various cultures.

The next study is done by Thanasoulas (1999). In his research study entitled as "Why can't a woman be more like man?", he has concluded that women most use the standard version of language and in fact the type they choose is politer than men. He defined language as a valuable social behavior that is representative of a complicated network of social, political, cultural and psychological communications in society. The difference in men and women language is rooted in the different status they take. Some linguists believe that since women are secondary in society, they choose the standard version of Language to improve their social status and value. The second reason of women's standard usage of language is related to their way of behavior in society; women need to represent appropriate behavioral patterns in society and they attempt to maintain their reputation and social value by utilizing the appropriate linguistic expressions. The third reason in their use of correct linguistic expressions is that they not only consider their own reputation in communication but also the reputation of their interlocutors is of significance for them. Therefore, they prevent any conflict and seek for building relationship with others. Another research has been done by Salmani Nodushan (2009). In this study, entitled as "Persian native speakers' requests: maintaining face implicitly", he concluded that direct requests are diminished when social distance is considerable between interlocutors and when the social distance do not exist, they tend to use direct requests as a sign for intimacy and solidarity.

Shahidi Tabar (2011) in a study entitled as "Indirectness and politeness in Turkish- Persian bilingual and Persian monolingual requests" sought to find out why most of the Iranian-Turkish speakers consider Persian speakers too straight and even impolite. He believed that to transfer pragmatic factors, a cross-cultural comparison is necessary. Other significant issues in this study are the ways of preparing the ground and polite address terms. The final research has been done by Akbari (2003). In this research entitled as "The realization of politeness principle in Persian" he studied swearwords in Persian language. He asserted that swearing has a negative relationship with education; the more the degree of education, the less the use of wear words. Thus, he concluded that educated people believe in what they say. Another finding of his study is the use of prayer words to encourage listener to cooperate with speaker. To answer the question "Do Persian speakers use the same approaches mentioned in Brown and Levinson (1987) model?" Akbari (2003) remarked "using the mentioned patterns is different in different cultures; however, in some situations, speakers of different languages treat equally". He also mooted that women use more emotional words than men.

\section{LITERATURE REVIEW}

\section{A. Politeness Principals}

In every communication or human interaction particular linguistic means are used in order to show an awareness of face regarding social distance (Yule, 1996). The most valuable theory about politeness, made based on cooperative principal, is for Brown and Levinson (1987) which is focused on face maintenance of the individuals. According to this theory, everyone has two kinds of face:

Positive face: The desire to be liked and appreciated in social interactions.

Negative face: The desire of individuals not to be imposed on or intruded.

Face: The self-concept of every individual is called face (Yule, 1996). In other words, face is the image that society has of individuals.

Face Maintenance: In every social interaction, individuals behave in a way to meet their own expectations of their face or realize their "face wants" (Ibid). 
Face Threatening: every expression or statement that threatens individuals' face (Ibid).

\section{B. Politeness}

Codification of observance of politeness theory is one of the most important aspects of the evolution in language (Brown \& Levingston, 1987, p. 321). They were severely affected by Goffman's ideas and Grice linguistic model, meaning that they believed that the politeness phenomenon is the factor of a kind of communication that persons or different nations make with each other. Yule (1986) considers politeness as a fix concept like; polite social manner or etiquette. Linguistics, sociologists and linguistic sociologists provide various definitions of politeness. Politeness bears different meanings in different contexts. The purpose of this study is the concept of politeness in linguistic context or, in other words, linguistic politeness. Linguistic sociologists usually define politeness with face. politeness is one of the main reasons that make people sometimes express their wants indirectly; that is, saying them implicitly".

Yule (1996) defined politeness as "politeness could be considered a static concept like polite social behavior or etiquette. It is also possible to recognize various general principles for politeness in a particular culture. He believes that politeness is a concept not a nature. However, politeness is the subtlety of act and speech. Politeness is definable in both act and speech. As not stepping up against an elder one or canceling your plan due to an uninvited guest are signs of politeness (practical politeness), speaking subtly and beautifully are likewise signs of politeness (lingual politeness). Besides, politeness is not different in different cultures rather politeness definitions vary in them. Politeness, thus, is an exact, beautiful and subtle act or speech." Brown and Levinson (1987, p. 62) mentioned two kinds of politeness raised from the concept of face. Positive face: including the need of individuals to be liked and accepted in various groups. Negative face: the need of the individuals to be independent, free and not to be imposed on by others.

\section{Situational Context of Language}

"Situational context" was first introduced by Malinowski (1923), the Polish anthropologists who lived most of his life in England. By situational context, Malinowski mooted a particular theory about meaning and language. In his study of meaning, situational context was the basis of his approach. He believed that the meaning of every utterance is represented in its situational context so that he correspond meaning to usage (Aghagolzadeh, 2001, p. 22, cited in Dinneen, 1967, p. 300). Firth (1950) posited that meaning is the "role" in the "context". In other words, the meaning of a sentence or expression isn't composed of the meanings of every single word rather it is the role the sentence plays in a specific context. Firth was almost affected by Malinowski who posited the concept of situational concept previously. Firth (1950) considers situational context not only as a means to express meaning but also as a descriptive language methods. He likewise has considered grammar another way of describing language, of course with different form and similar abstract nature since linguistics composes a hierarchy of such methods dealing with context. According to Firth, all the linguistic explanations, including phonology, grammar and also situational context, represent meaning. Another Firth's achievements of linguistic theory are his influence on linguistic sociology. According to him, the point of significance in linguistics is language in its real usage. Firth remarked that language usage is one of the important aspects of human life and it has significant role in social communications.

\section{Discourse Analysis}

Discourse Analysis is that how the sentences in the (spoken and written language) cause producing the larger meaningful unites like: text, dialogue or interview. Cook (1989, p. 6) says: Discourse Analysis is a search to find whatever that gives cohesion to the discourse. He believes that discourse approach of face-to-face conversation type, is an analytical method that typically is included in the range of micro discourse analysis not (macro)'s one.

\section{E. Pragmatics}

Van- dijk (1989, p. 189) believes that the main purpose of Pragmatics is the study of the relationship between the linguistics elements and their users. In his opinion, pragmatics is a part of a linguistic theory. Crystal (1992, p. 310) calls the study of language in term of the users as Pragmatics. He believes that Pragmatics is the choice of the sentence structure according to the restrictions in the use of language in the social interactions and the effects that this choices have on the other participants in the communication on the behalf of the speaker.

\section{F. Grice Principle}

Grice (1957) introduced four fundamental principles as dialogue strategies about the way of language usage in peoples' communications. All of these principles make cooperative principle.

The four strategies are as follows:

1. Quality principle: try to speak honestly and reasonable in your turn of speech, means that avoid to say whatever you suppose a lie and don't say something that you haven't enough evidences and reasons.

2. Quantity principle: the share of yours in the conversation must to be appropriate and of adequate information, speak not much more and not much less than it is necessary.

3. Communication principle: try your speech be related to the topic, i.e. speak related to the topic.

4. Manner principle: speak clear, concise, regular and to the point. 


\section{DATA ANALYSis}

For analyzing the data, a questionnaire was designed that consist of linguistic and metalinguistic factors based on pragmatics and politeness principles and also Grice fundamentals. This questionnaire can be effective for the way employer - customer interact. Then each of the 100 participants are asked to evaluate their interaction based on the questionnaire's questions. After that, the answer to the questions will be collected and stratify and the number also the percentage of the effective factors was obtained. As in the table 1 are shown. It should be noted that each factor including linguistic and non-linguistic was evaluated by positive or negative values.

TABLE 1:

EFFECTIVE FACTORS IN THE EMPLOYEE-CLIENT SPEECH INTERACTIONS

\begin{tabular}{|c|c|c|c|c|c|c|}
\hline Row & Effective Factors & Linguistic & Metalinguistic & Value & Number & Percentage \\
\hline 1 & face to face interactions & & $*$ & + & 89 & $\% 89$ \\
\hline 2 & greetings & $*$ & & + & 87 & $\% 87$ \\
\hline 3 & making utterance & $*$ & & + & 62 & $\% 62$ \\
\hline 4 & turn taking in discourse & * & & + & 52 & $\% 52$ \\
\hline 5 & tolerance in listening to discourse & & $*$ & + & 41 & $\% 41$ \\
\hline 6 & paying enough attention to client's discourse & & $*$ & + & 38 & $\% 38$ \\
\hline 7 & speech interruption & $*$ & & - & 35 & $\% 35$ \\
\hline 8 & conversation on phone meanwhile interacting & & $*$ & - & 28 & $\% 28$ \\
\hline 9 & ambiguity & $*$ & & - & 21 & $\% 21$ \\
\hline 10 & being talkative & $*$ & & - & 17 & $\% 17$ \\
\hline 11 & smiling & & $*$ & + & 14 & $\% 14$ \\
\hline 12 & lingering & & $*$ & - & 12 & $\% 12$ \\
\hline 13 & staff joking with each other in their discourse & $*$ & & - & 5 & $\% 5$ \\
\hline 14 & struggling among staff & $*$ & & - & 2 & $\% 2$ \\
\hline 15 & quantity (talk to clients less than necessity) & $*$ & & - & 2 & $\% 2$ \\
\hline
\end{tabular}

As it can be seen in the table, the highest percent of using efficient factors was related to greetings that this positive value was done in the mount of $89 \%$, and the lowest was related to struggling during discourse with just $2 \%$. Using face to face interactions was satisfactory, but speech interruption was seen approximately high. Speech production also was seen by the employers and they observed turn taking in the speech to the right rate.

\section{CONCLUSION}

Bing honest in speech (observing the first Grice's principle) is very crucial. Speak in an equivocal manner and also with sarcasm (violating the fourth principle) make clients annoyed. Speaking as needed, (observance of the second rule) and related to the subject (observance of the third rule) is of the most important concerns of the clients during official discourses. Any kind of joking speech such as; a joke or prank among the employers in front of the client (violating negative politeness) is an impolite deed. Thus every correct discourse ought to be done considering the age, education and social condition of the client in offices, and this will not occur unless interact with clients face to face and observe politeness in the discourse. Employers are to use proper turn takings and on time utterance production. Pay less attention to the client shall be a lack of respect. This can be speaking to a colleague or telephoning. It had better for staff to speak related to the subject during the speaking to the client (observance of the third rule). It has two reasons as: 1Avoid making any mistake in the administrative affairs. 2- Avoid make any interference in others private affairs (observing negative politeness). According to what we gained from the surveys conducted, every wait for questioning from the part of customers is considered kind of impoliteness. They don't like to wait so long when talking to employees. Moreover, eye contact and face to face interaction is of significance for them. They usually choose an employee who smile, respect them and speak very politely. They get angry with the employees who don't understand them more than once and take it as sign of impoliteness. They also hate speaking vaguely and ironically since everything needs to be clear in administrative situations. It is expected of employees to transfer everything completely to customers.

After the data analysis and statistical study have been done, results suggest that all of the clients in non-governmental offices believe that face to face interactions, turn taking, and among the linguistic roles: making utterance, meta lingual and paralinguistic factors should be use while giving services to the clients. They expect the employers to use proper observing politeness strategies and face saving in format of positive and negative politeness in pragmatics to make better impressions. Following conducting the current study we hope that the politeness principles to be revised, in order to governmental offices do better in offering services to their clients, and this study can make the best response to the both employer and client, and leads to the both consent. At last, it can be added that the results and findings of this study can be used in organizations, ministries and companies that dealing with the clients, and can make an impression on the administrative discourse improvement.

\section{REFERENCES}

[1] Aghagolzadeh, F. (2001). An analysis of critical discourse. Tehran: Scientific \& Cultural Publication. 
[2] Akbari. (2003). The realization of Politeness Principles in Persian, Unpublished Master Thesis on General Linguistics, Islamic Azad Islamic University, Science and Research Branch, Tehran.

[3] Blum-Kulka, S. (1987). "Indirectness and Politeness in Request: Same or Different?" Journal of Pragmatics: North Holland, 11, pp 131-146.

[4] Brown, P. and Levinson, S. (1987). Some universals in language usage, Cambridge: Cambridge University Press.

[5] Crystal, D. (1992). Introducing Linguistics, London: Penguin English.

[6] Dinnen, F. P. (1967). Introduction to General Linguistics, New York: Holt Rinehart.

[7] Felix, C. and Defer, B. (2005). "Indirectness and politeness in Mexican requests", In Selected Proceedings of the 7 th Hispanic Linguistics Symposium, David Eddington (ed.), 6678. Somerville, M A: Cascadilla Proceedings Project. http://www.lingref.com/cpp hls/7/ paper1087.pdf (accessed 1 March 2008).

[8] Firth, J. R. (1950). "Personality and language in society, Sociological Review42:37-52. Reprinted in J. R Firth (1957) Papers in Linguistics 1934-1951, 177-189. Oxford, Oxford University Press.

[9] Grice, H. P. (1957). Logic and conversation, In Peter Cole and Jerry Morgan (ed.) Syntax and Semantics, Volume 3: Speech Acts. New York: Academic Press, pp: 41-102.

[10] Leech, G. N. (1983). Principles of Pragmatics, London: Longman.

[11] Malinowski, B. (1923). "The problem of meaning in primitive Language”, In: C. K. Oghden and A. Richards (eds.). The meaning of Meaning, Oxford, pp: 296-336.

[12] Marti, L. (2006), Indirectness \& Politeness in Turkish- German bilingual and Turkish monolingual requests. Cambridge: Cambridge University Press.

[13] Ogiermann, E. (2007). "Indirectness and politeness: a contrastive study of requests in the interlanguages of German, Polish and Russian students of English", Paper presented at the $19^{\text {th }}$ International Conference on Foreign/Second Language Acquisition, Szczyrk, Poland, 17-19 May.

[14] O'Grady, W. (1989). Contemporary Linguistics: An Introduction. (3rd ed.) Bedford, St. Martin's Press.

[15] Pennycook, A. (1989). "The Concept of Method, Interested Knowledge, and the Politics of Language Teaching", TESOL Quarterly, Vol. 23, No. 4., pp. 589-618.

[16] Salmani Nodushan, M. (2009). Persian native speakers' requests: maintaining face implicitly. Unpublished master thesis on General Linguistics: The University of Isfahan. Isfahan.

[17] Shahiditabar, M. (2011). Indirectness and politeness in Turkish-Persian bilingual and Persian monolingual requests. Unpublished master thesis on General Linguistics, Islamic Azad University, Science and Research Branch, Tehran.

[18] Van - Dijk, T. A. (1989). "Structures of Discourse and Structures of Power" in J. A. Anderson (ed.) Communication Yearbook 12 (Newbery Park, CA: Sage), pp: 18-59.

[19] Yule, G. (1986). The study of language, Cambridge: Cambridge University Press.

[20] Yule, G. (1996). Pragmatics, London: Oxford university press.

Kaveh Hedayat was born in Iran in 1977. He is BS of English Language literature at University of Tehran, and MA of linguistics at Science and Research Branch, Islamic Azad University. He is now, PhD student of linguistics at Central Tehran Branch, Islamic Azad University, Tehran, Iran.

Foroogh Kazemi was born in Iran in 1974. She is head of linguistics department and associate professor of linguistics in Central Tehran Branch, Islamic Azad University in Iran. She has published 38 articles (cited in google scholar) and 15 books in linguistics. Dr. Kazemi has been advisor, reader and referee of many linguistic theses and judge of articles in journal of linguistics. She is a member of research council in faculty of foreign languages at Central Tehran Branch. She is also a member of editorial board, quarterly of language and literature: Parneyan Kheyal. Her areas of interest are functional linguistics, sociolinguistics, typology and discourse analysis. 